\title{
Design, saúde e integração social no enfrentamento da pandemia Covid-19: case máscara de alta proteção AZUL-A98
}

Design, health and social integration in coping with the Covid-19 pandemic:

case of high protection mask "AZUL-A98

Thassiana de Almeida Miotto Barbosa

Universidade Estadual de Londrina - UEL

thassimiotto@gmail.com

s

Danielly Negrão Guassú Nogueira

Universidade Estadual de Londrina - UEL

dani.saude@yahoo.com.br.x

Lucimar de Fátima Bilmaia Emídio

Universidade Estadual de Londrina - UEL

lucimaremidio@gmail.com

Seila Cibele Sitta Preto

Universidade Estadual de Londrina - UEL

cibelesittap@gmail.com $\mathbf{x}$

Patrícia de Mello Souza

Universidade Estadual de Londrina - UEL

patriciademellosouza@gmail.com

Valdirene Aparecida Vieira Nunes

Universidade Estadual de Londrina - UEL

valvieira01@yahoo.com.br

\section{PROJËTICA}

\section{COMO CITAR ESTE ARTIGO:}

BARBOSA, T. A. M.; NOGUEIRA, D. N. G.; EMÍDIO, L. F. B.; PRETO, S. C. S.; SOUZA, P. M.; NUNES, V. A. V. Design, saúde e integração social no enfrentamento da pandemia Covid-19: case máscara de alta proteção AZUL A-98. Projética, Londrina, v. 11, n. 1, p. 276-308, 2020. Supl.

DOI: $10.5433 / 2236-2207.2020 v 11 n 1$ suplp276

Submissão: 29-04-2020

Aceite: 04-05-2020

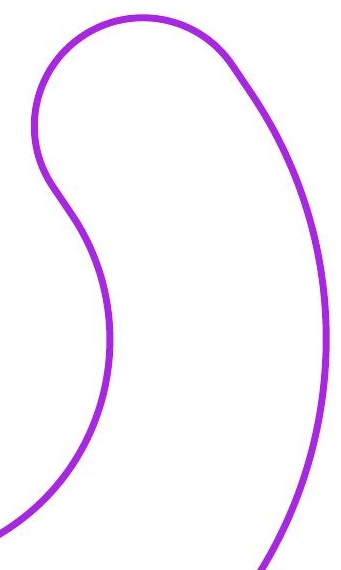


Design, saúde e integração social...máscara de alta proteção AZUL-A98

BARBOSA, T. A. M. et al

RESUMO: O presente trabalho discorre sobre o desenvolvimento de uma máscara cirúrgica de alta proteção, destinada aos profissionais do Hospital Universitário da Universidade Estadual de Londrina, durante a Pandemia da Covid-19. Por meio da integração do conhecimento entre as áreas de design de moda e enfermagem, a pesquisa aplicada de abordagem qualitativa, utilizou o processo de design para desenvolver a máscara AZUL-A98, que contempla aspectos ergonômicos, funcionais, estéticos e de inovação, proporcionando alto grau de vedação, filtração e respirabilidade, para maior segurança dos usuários.

Palavras-chave: Design de moda. Modelagem. SMS. Saúde. Máscara AZUL-A98.

ABSTRACT: This work discusses the development of a high-protection surgical mask, intended for professionals at the University Hospital of the State University of Londrina during the Covid-19 pandemic. Through the integration of knowledge between the areas of fashion design and nursing, and by means of an applied research with a qualitative approach, we used the design process to develop the "AZUL-A98" mask, which includes ergonomic, functional, aesthetical and innovative aspects, providing high degrees of sealing, filtration and breathability, for greater user safety.

Keywords: Fashion design. Modeling. SMS. Health. AZUL-A98 mask.

\section{INTRODUÇÃO}

O contexto imposto pela pandemia da Covid-19, causada pelo novo Corona Vírus (SARS-CoV-2), determinou uma série de medidas restritivas à população mundial. Questões referentes à diminuição do contágio, isolamento social, eficiência de medicamentos e uso de Equipamentos de Proteção Individual (EPI) vem sendo amplamente discutidas por diversos setores políticos e econômicos, em busca de soluções efetivas para a proteção da vida. 
Projética, Londrina, v. 11, n. 1, supl. Design de Moda, p. 276-308, maio 2020

Desde janeiro do corrente ano, a Organização Mundial de Saúde (2020) recomenda o uso de máscaras, tanto para a comunidade médica, que lida diretamente com pacientes infectados, quanto para a população em geral, como medida de prevenção da doença. Esta recomendação gerou a escassez na oferta de EPI, em âmbito global, causando períodos de desabastecimento de hospitais e unidades básicas de saúde.

Neste contexto, prezando por assegurar a proteção dos profissionais de saúde que atuam no seu Hospital Universitário (HU), a reitoria da Universidade Estadual de Londrina (UEL), representada pelo vice-reitor ${ }^{1}$, solicitou à coordenação do Curso de Design de Moda, a produção de máscaras como uma das ações planejadas de combate e enfrentamento da pandemia.

Assim, em meio às pesquisas para encontrar soluções para a demanda, uma equipe formada por docentes do curso de Design de Moda ${ }^{2}$, em busca de especialistas em saúde que pudessem integrar-se ao grupo, estabeleceu contato com uma docente do Curso de Enfermagem³ ${ }^{3}$ que também atua como enfermeira no $\mathrm{HU}$ e, imediatamente, aceitou a parceria para o desenvolvimento de máscaras para a proteção dos funcionários do hospital.

[1] Prof. Dr. Décio Sabbatini Barbosa - Vice-reitor da Universidade Estadual de Londrina - UEL.de Estadual de Londrina

[2] Profa. Me. Thassiana de Almeida Miotto Barbosa; Profa. Me. Valdirene Aparecida Vieira Nunes; Profa. Dra. Patrícia de Mello Souza e Profa. Dra. Lucimar de Fátima Bilmaia Emídio - Departamento de Design-UEL.

[3] Profa. Dra. Danielly Negrão, da área perioperatória - Departamento de Enfermagem-UEL 
Design, saúde e integração social...máscara de alta proteção AZUL-A98

BARBOSA, T. A. M. et al

Desta parceria, surgiu a indicação do material utilizado na confecção das máscaras, um TNT de uso hospitalar conhecido como SMS (Spunbonded + Metblown + Spunbonded). Estudado há mais de 8 anos pela docente ${ }^{4}$, este tecidonão-tecido, que era considerado um refugo dentro do centro cirúrgico do $\mathrm{HU}$, foi identificado como material ideal para o projeto, uma vez que suas características cumpriam os critérios estabelecidos pela normatização brasileira do EPI.

Diante deste cenário, a equipe de docentes propôs a fabricação de máscaras cirúrgicas em SMS, para suprir a demanda inicial do (HU). Após esta ação, a Comissão de Controle de Infecções Hospitalar (CCIH) solicitou o desenvolvimento de uma nova configuração de máscara, considerando a utilização de barreira dupla de material filtrante e de maior vedação que a oferecida pela máscara cirúrgica, para ampliar a proteção aos trabalhadores.

A ABNT NBR 15052, define que as máscaras podem ser classificadas em: máscaras cirúrgicas, máscaras cirúrgicas de alta proteção e respiradores (conforme ABNT NBR 13698). Buscando atender às especificações técnicas para a confecção de máscaras cirúrgicas de alta proteção, conforme solicitado pela $\mathrm{CCIH}$, a equipe procurou soluções rápidas, de alta proteção e de baixo custo. (ASSOCIAÇÃO BRASILEIRA DE NORMAS TÉCNICAS, 2004, 2017).

Utilizando-se do processo de design e embasando-se na normatização brasileira para EPIs, ABNT NBR 15052 e ABNT NBR 13697, desenvolveu-se uma série de estudos de configuração e viabilidade do produto, para atender aos requisitos de filtração, respirabilidade, vedação, fixação e ajuste facial. (ASSOCIAÇÃO BRASILEIRA DE NORMAS TÉCNICAS, 2004, 2010).

[4] Lucimar de Fátima Bilmaia Emídio - Doutora, Universidade Estadual de Londrina 
Projética, Londrina, v. 11, n. 1, supl. Design de Moda, p. 276-308, maio 2020

Aliando tais características a um processo guiado por experimentações por meio de técnicas de design e modelagem, foram construídos diversos protótipos e realizados testes de dimensionamento para validação do projeto, resultando no produto máscara "AZUL-A98", caracterizada como cirúrgica de alta proteção, não estéril, sendo de uso único e descartável, indicada para profissionais da saúde que atuam em setores hospitalares de maior exposição, por ter uma barreira dupla e melhor vedação no rosto.

Assim sendo, objetiva-se mostrar as principais contribuições do design como atividade projetual multidisciplinar - que neste estudo integra saberes das áreas de design de moda e enfermagem, além de parcerias de âmbito social - voltada a soluções de problemas diversos; bem como a importância dos conhecimentos de modelagem atrelados ao processo de design desde as fases iniciais, imprescindíveis para contribuir com soluções inovadoras que atendam às diversas funções requeridas, conforme demandas específicas de produtos e contextos - a exemplo destes, relacionados à pandemia causada pela Covid-19.

É importante ressaltar, que todas as ações aqui apresentadas só puderam ser desenvolvidas por encontrar respaldo na Resolução 356/2020, publicada pela Agência Nacional de Vigilância Sanitária (ANVISA) que, devido ao agravamento da crise sanitária, permite a confecção de máscaras em caráter de excepcionalidade.

\section{PARÂMETROS TÉCNICOS E PRINCÍPIOS METODOLÓGICOS ENVOLVIDOS NO PROJETO MÁSCARA AZUL-A98}

Para a realização deste estudo utilizou-se da técnica da pesquisa-ação a qual possui estreito vínculo com uma ação ou resolução de problemas coletivos no qual os pesquisadores e participantes representativos estão envolvidos na pesquisa de modo cooperativo (THIOLLENT, 2011). 


\section{Design, saúde e integração social...máscara de alta proteção AZUL-A98}

BARBOSA, T. A. M. et al

A pesquisa-ação é orientada em função de uma composição de objetivos de descrição e intervenção. É uma pesquisa aplicada onde trabalha-se com quatro grandes fases: a exploratória, a de pesquisa aprofundada, a de ação e de avaliação. Esta técnica é considerada como um mecanismo de retroalimentação dos resultados da investigação para os usuários/clientes, corrobora Thiollent, (2009). Utilizou-se de uma abordagem metodológica qualitativa a qual desenvolve-se numa situação natural, oferecendo riqueza de dados descritivos, bem como focalizando a realidade de forma complexa e contextualizada.

A investigação, também se identifica com o estudo de caso, já que possui o objetivo de apreender determinada situação e descrever a complexidade de um fato (LAKATOS; MARCONI, 2017). Nesse sentido a partir de revisão bibliográfica de natureza exploratória associada à experiência profissional da equipe de docentes da área de modelagem do curso de Design de Moda da UEL, foi possível entrelaçar as duas vias de pensamento de design e de modelagem na resolução projetual da máscara AZUL-A98, objeto deste estudo.

Acerca dos parâmetros para organizar o pensamento de design, destacase as orientações de Sanches (2017) que aponta três focos essenciais para conduzir um projeto de design: explorar o contexto, identificando relações e diretrizes (DELIMITAR); experimentar combinatórias das diretrizes e multiplicar as possiblidades (GERAR); selecionar e canalizar as possibilidades para uma proposta factível (AVALIAR/CONSOLIDAR). A autora também destaca a experimentação material como meio eficaz de evolução do pensamento projetual no âmbito do vestuário, marcando a importância da modelagem para o refinamento dos objetivos, a geração de ideias e a exploração de possibilidades de interação entre artefato e usuário. 
Projética, Londrina, v. 11, n. 1, supl. Design de Moda, p. 276-308, maio 2020

Para Emídio (2018), é por meio da modelagem e dos materiais que se tem o contato direto do produto de vestuário com o corpo do usuário e que, por isso, estes produtos têm a capacidade de afetá-lo sobre uma série de aspectos psicológicos e fisiológicos. A autora salienta sobre a importância de incorporar os contributos das ciências da anatomia, antropometria, ergonomia, sobretudo atreladas aos processos metodológicos do design de moda desde as fases iniciais, uma vez que estas fornecerão parâmetros para se trabalhar de maneira sistematizada com as questões referentes à estrutura humana, suas proporções e possibilidades de movimento, além de possibilitar aplicação de teorias e princípios metodológicos que visem otimizar o bem estar físico e emocional do usuário, com relação ao processo de uso do produto.

lida (2005), Moraes e Mont'Alvão (2010) enfatizam que o produto, direta ou indiretamente, entra em contato com as pessoas e tem a finalidade de ser utilizado efetivamente pelo usuário, por isso, estabelecem as qualidades essenciais que os produtos devem apresentar: qualidades técnicas, que dizem respeito a eficiência com que o produto executa a função; as ergonômicas que garantem uma boa interação do produto com o usuário, relaciona-se com os aspectos de conforto, segurança, facilidades de uso e manuseio; e as estéticas que devem atrair e comunicar-se com o usuário/consumidor.

Desta forma, cabe incluir aqui, as contribuiç̧ões da ergonomia para os estudos da modelagem, a qual pode ser representada tanto de forma bidimensional geométrica/plana, quanto tridimensional, em duas dimensões e finalidades segundo Emídio (2018), sendo: 1) dimensão técnico-criativa e 2) técnico-produtiva. 


\section{Design, saúde e integração social...máscara de alta proteção AZUL-A98}

BARBOSA, T. A. M. et al

Segundo a autora supracitada, na dimensão técnico-criativa a modelagem está vinculada ao processo de concepção do produto, no qual, converge-se a natureza técnica e criativa da modelagem, destacando o uso da modelagem tridimensional (moulage) como recurso criativo, de experimentação e estudo, como meio de representação e de verificação das ideias geradas. Nesta dimensão, a autora enfatiza a importância do conhecimento técnico de modelagem para ampliar possibilidades criativas no processo de concepção de produtos.

Já a dimensão técnico-produtiva, segundo Emídio (2018), está diretamente ligada à produção do vestuário. Nela, destaca-se os conhecimentos técnicos relacionados a atividade de modelagem geométrica bidimensional/plana, considerada a principal técnica utilizada nas indústrias de confecção, por meio da qual possibilita-se a reprodutibilidade dos produtos, fundamental ao sistema de produção em série.

Logo, nessa dimensão, a modelagem é entendida como condutora do processo de produção; como recurso técnico de construção; de registro e reprodução de modelos para fins de produção industrial; como potencializadora no atendimento às funções práticas do produto junto ao usuário; bem como fundamental para a assertividade do processo de produção industrial dos produtos (EMÍDIO, 2008).

Por isso, no âmbito do projeto da máscara AZUL-A98, a modelagem esteve atrelada ao processo de design desde as fases iniciais. Contudo, primeiramente buscou-se compreender as características técnicas do SMS - material utilizado para a confecção das máscaras - e os critérios estabelecidos para a produção de EPI para, então, buscar soluções inovadoras para o produto em questão. 
Design, saúde e integração social...máscara de alta proteção AZUL-A98

BARBOSA, T. A. M. et al

\section{TECIDO-NÃO-TECIDO DO TIPO SMS COMO SOLUÇÃO PARA CONFECÇÃO DE MÁSCARA CIRÚRGICA DE ALTA PROTEÇÃO}

Ao referir-se aos diversos tipos de desempenho dos materiais, Souza (2013) destaca o sensorial e o ambiental e ressalta que cabe ao projetista, não só conhecer os materiais sob o ponto de vista técnico, como também estar atento a outras propriedades, em especial, aquelas vinculadas à percepção.

Buscando atender às especificações técnicas para a confecção de máscaras cirúrgicas de alta proteção, conforme a ABNT NBR 15052, o grupo de pesquisadoras optou pela utilização do SMS, um tecido-não-tecido de uso hospitalar, como suporte têxtil principal da máscara. Esse material é resultado da fusão térmica de 3 camadas (Spunbonded + Metblown + Spunbonded) compostas por 100\% polipropileno. Graças à trama especial, o SMS possui uma barreira microbiológica, validada pela ABNT NBR 14783, e assegura eficiência de filtragem de partículas (EFP) maior que $98 \%$ e filtragem bacteriológica (BFE) acima de 95\%. (ASSOCIAÇÃO BRASILEIRA DE NORMAS TÉCNICAS, 2002, 2004).

Devido ao caráter emergencial do projeto, uma das questões consideradas na definição dos materiais foi a facilidade de aquisição, uma vez que a produção das máscaras se estenderia durante todo o período da pandemia. Por ser um material já utilizado pelo hospital, como embalagem estéril de equipamentos cirúrgicos, e com possibilidade de ser reaproveitado após seu uso inicial, o SMS foi considerado um material seguro e sustentável.

Esta ação foi pensada, considerando as propostas da Agenda Global para Hospitais Verdes e Saudáveis - AGHVS (KARLINER; GUENTHER, 2012), que constitui a principal referência para convergência de esforços na busca de soluções e envolvimento de profissionais de saúde e de diversas áreas na busca de estratégias que promovem tanto a saúde pública como a sustentabilidade ambiental, está articulado com os Objetivos de Desenvolvimento Sustentável (ODS). 
Projética, Londrina, v. 11, n. 1, supl. Design de Moda, p. 276-308, maio 2020

O Hospital Universitário da Universidade Estadual de Londrina, tem um projeto de pesquisa denominado de projeto Muda $^{5}$ que desenvolve ações nos 10 pilares da AGHVS e dentro do pilar de Resíduos, tem a proposição de uma estratégia de reaproveitamento de materiais com dificuldades de reciclagem, como é caso do SMS, que é utilizado para embalagem cirúrgica estéril.

Por meio do Projeto Muda $^{6}$, dentro das sete salas de cirurgias, onde o material ainda se encontra estéril, são propostas seis etapas de captura segura do material antes do início da cirurgia, pela equipe de enfermagem: lavagem das mãos, abertura com técnica asséptica, guarda temporária em carrinho auxiliar, retirada de fitas adesivas, dobradura do SMS, armazenamento em caixa plástica e container de inox (Figura 1).

[5] A Profa. Dra. Danielly Negrão, Departamento de Enfermagem - UEL, coordena o projeto de pesquisa "Sustentabilidade e Gestão de Custos em Serviços de Saúde", denominado como Projeto Muda, que estuda a destinação adequada e a matéria prima das embalagens estéreis e atua como parceira do projeto de pesquisa "Logística reversa de resíduos têxteis industriais e pós consumo: design aplicado a sistemas e serviços sustentáveis e modelos de negócios", coordenado pela docente Profa. Dra. Susana Barreto Martins, pesquisando novas possibilidades de destinação e soluções de baixo custo dessas embalagens.

Seila Cibele Sitta Preto - Doutora, Universidade Estadual de Londrina 
Figura 1 - Processo de separação do material

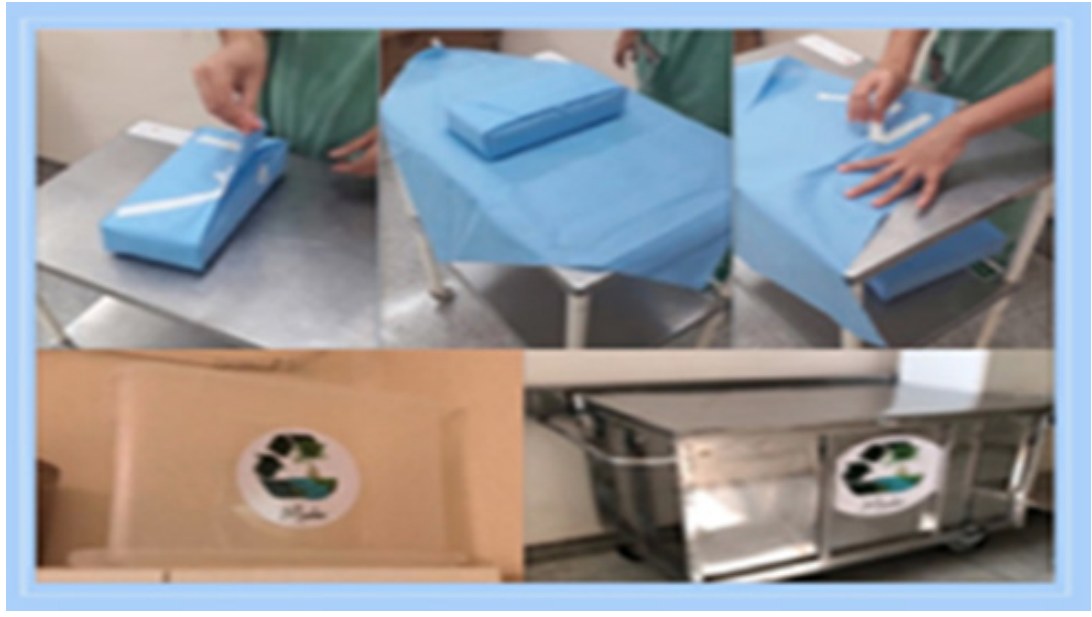

Fonte: acervo do Projeto Muda (2020).

Este processo possibilita o reaproveitamento do SMS, que já foi utilizado como embalagem estéril para a confecção de máscaras, uma vez que a trama do material não tem alteração estrutural e nem morfológica que possa interferir no elemento filtrante, esses resultados são inovadores e foram testados por meio de Microscopia Eletrônica por Varredura (MEV) nas máscaras confeccionadas com o material, uma vez que o produto proposto não é estéril.

Esta estratégia foi, então, adotada como uma solução rápida para este momento de falta de matéria prima, além de proporcionar a otimização de recursos e a eliminação de desperdício, criando uma prática sustentável. Até o momento, as máscaras produzidas pelo projeto, foram confeccionadas com SMS novo, devido às doações recebidas de diversos parceiros. Esta ação permitiu que o (HU) fizesse um estoque reserva dentro no plano de contingência da pandemia. 
Projética, Londrina, v. 11, n. 1, supl. Design de Moda, p. 276-308, maio 2020

Figura 2 - Processo de esterilização antes do primeiro uso da máscara AZUL-A98

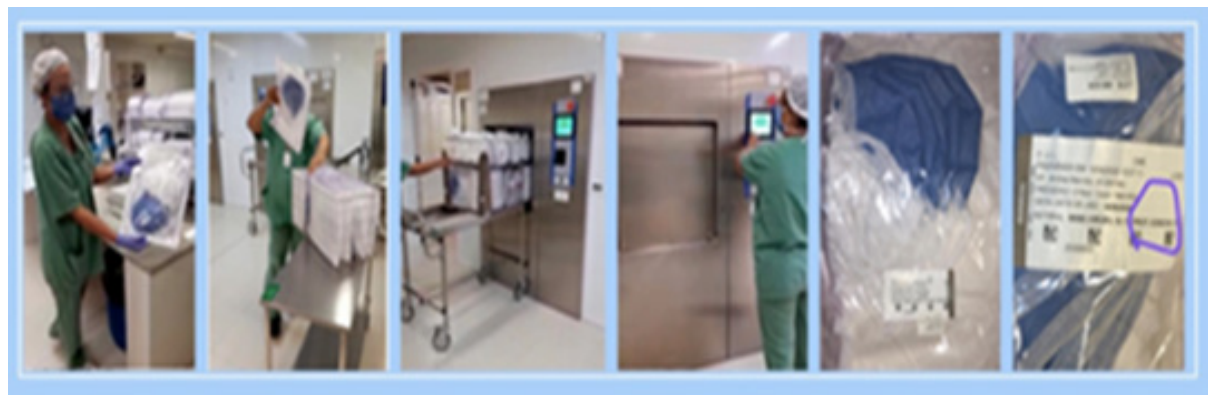

Fonte: acervo das autoras (2020).

Cabe enfatizar que, após o processo de fabricação, devido à manipulação por diversas mãos que trabalham na linha de produção, as máscaras AZUL-A98 são direcionadas para a Central de Material e Esterilização (CME) do HU e passam por processo de esterilização em Autoclaves de Vapor Saturado sob pressão (Figura 2), antes do primeiro uso, sendo que a máscara desenvolvida é de uso único e descartável, não sendo recomendado o reprocessamento da mesma em nenhuma hipótese.

\section{A TRAJETÓRIA PROJETUAL}

\subsection{REQUISITOS DE PROJETO E EXPERIMENTAÇÕES REALIZADAS}

Uma vez definido o material, procedeu-se à investigação acerca dos EPIs. Inicialmente analisou-se os princípios de vedação e acomodação dos respiradores disponíveis no mercado e, na sequência, os equipamentos de proteção já utilizados pelos profissionais do $(\mathrm{HU})$, para estabelecer e respeitar os padrões existentes, mediante o estudo técnico destes similares no que se refere a requisitos de vedação, ergonomia, ajuste facial, conforto tátil, térmico e visual. 


\section{Design, saúde e integração social...máscara de alta proteção AZUL-A98}

BARBOSA, T. A. M. et al

A partir de então, iniciou-se a fase projetual de experimentação que contemplou os seguintes diretrizes: a) exploração do material para adaptação da forma do produto ao rosto do usuário, de modo a respeitar a anatomia côncava e convexa da face; b) estudos de modelagem, tridimensional e plana, para criar ajustes e princípios de extensão e redução, a fim de eliminar qualquer costura ou recorte da extensão "nariz-queixo"; c) exploração da forma para adequação do volume de ar com pregas permitindo, também, o ajuste a diversos formatos de rostos; d) experimentação de mecanismos de ajuste para garantir a melhor adaptação e mais segurança na fixação do produto às diversas configurações e dimensões de rosto e cabeça. Considerou-se a utilização do sistema de amarração com tiras, clipe nasal e material filtrante, conforme ABNT NBR 15052 (ASSOCIAÇÃO BRASILEIRA DE NORMAS TÉCNICAS, 2004). A Figura 3 ilustra aspectos importantes desta fase experimental.

Em busca de contemplar, integralmente, o conjunto das necessidades especificadas - requisitos de projeto - e ampliar a gama de possibilidades a serem testadas foram, inicialmente, propostas cinco diferentes configurações de máscaras.

As experimentações iniciais (Figuras 3 e 4) indicaram que determinadas configurações se adequavam melhor que outras a diferentes formatos de rosto, o que interferia na maior ou menor capacidade de vedação, que por sua vez vinculava-se não só ao modo como as tiras eram amarradas (paralelas, cruzadas), mas onde se situavam (acima ou abaixo da orelha, em direção à nuca, ao meio ou topo da cabeça). 
Projética, Londrina, v. 11, n. 1, supl. Design de Moda, p. 276-308, maio 2020

Figura 3 - Experimentações iniciais

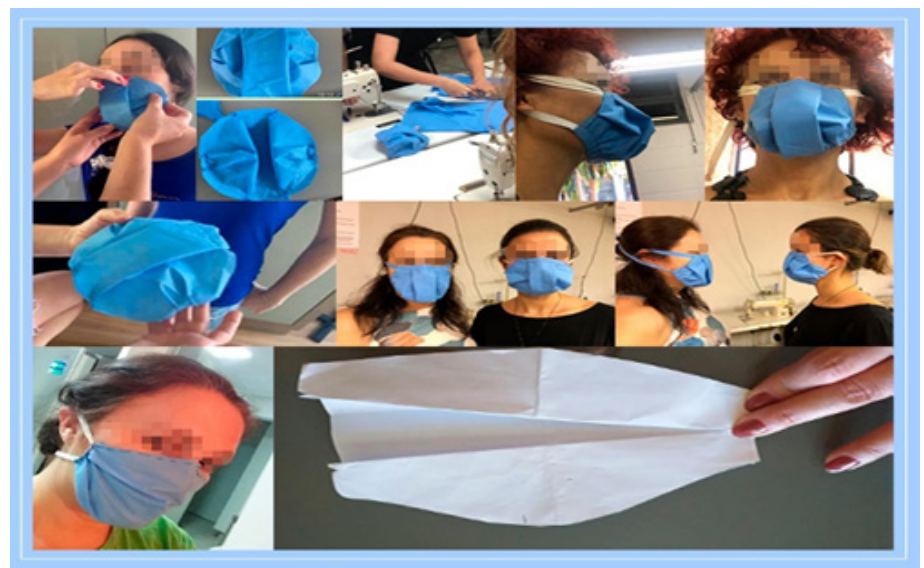

Fonte: acervo das autoras (2020).

Com relação à posição das pregas, as opções que continham este recurso distribuído ao longo da extensão inferior da máscara, apresentaram melhor vestibilidade e conforto respiratório se comparadas aos modelos de prega central. Esses, inclusive, foram recusados pelos usuários da área de saúde, em fase posterior de análise, devido a causar um estranhamento, especialmente por apresentar uma estética muito diferente dos modelos geralmente conhecidos e usados por eles.

Figura 4 - Verificações em diferentes tipos de rostos

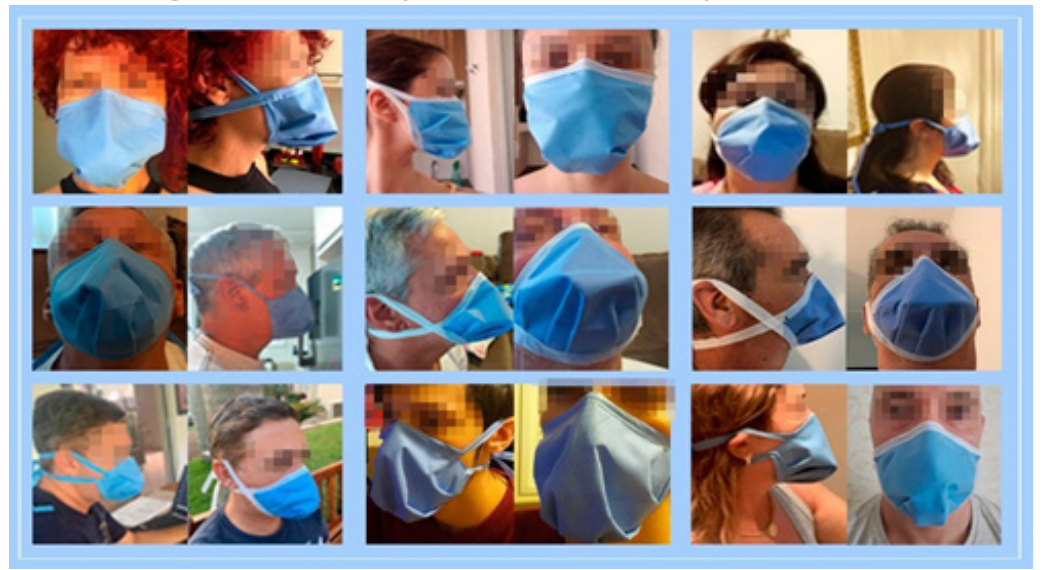

Fonte: acervo das autoras (2020). 
Design, saúde e integração social...máscara de alta proteção AZUL-A98

BARBOSA, T. A. M. et al

\subsection{A VALIDAÇÃO DO MODELO MÁSCARA AZUL-A98}

Segundo Baxter (2011), ao se alcançar uma solução para a configuração de um produto, é necessário verificar, primeiramente, se ele atende aos objetivos e requisitos do projeto. Uma das formas de realizar esta avaliação, segundo o autor, é por meio da construção de protótipos para teste e análise de uso do produto, a fim de conhecer possíveis falhas em seu funcionamento antes de sua produção em escala industrial.

Assim, a partir dos resultados das primeiras experimentações (Figuras 3 e 4) realizadas com as cinco opções de configurações propostas, selecionou-se as mais adequadas para serem verificadas em um contexto mais amplo e em situação de uso pelos profissionais para os quais estavam sendo projetadas.

Desta forma, para realizar a validação da máscara AZUL-A98, foram confeccionadas 85 unidades de protótipos, os quais foram submetidos a testes de usabilidade e análise, de acordo as seguintes etapas: a) confecção de protótipos para uso e análise dos mesmos, pela equipe de projeto e da Comissão de Controle de Infecção Hospitalar (CClH) do (HU); b) confecção de protótipos, para uso e análise da máscara por equipes de plantonistas do (HU); c) avaliação de uso, por meio do estudo de imagens e depoimentos dos usuários iniciais; d) correção formal do produto, com base nos critérios analisados; e) confecção de protótipos para nova rodada de uso e análise da máscara pela equipe de projeto e profissionais do (HU); f) configuração final do produto.

A fim de assegurar o cumprimento dos objetivos de projeto, foram selecionados, para participar dos testes de usabilidade, voluntários de ambos os sexos, de diferentes idades e tipos físicos, integrantes das diversas áreas do (HU), dentre os quais, a equipe da Comissão de Controle de Infecção Hospitalar (CCIH) solicitante do projeto em questão - que participou de todas as etapas dos testes e 
Projética, Londrina, v. 11, n. 1, supl. Design de Moda, p. 276-308, maio 2020

foi a responsável pelo parecer final sobre o protótipo escolhido. Esta validação foi realizada com a intenção de selecionar o protótipo mais adequado e garantir uma perfeita vedação e acomodação nos diversos biótipos analisados (Figura 5).

Figura 5 - Teste de usabilidade pelos profissionais de saúde

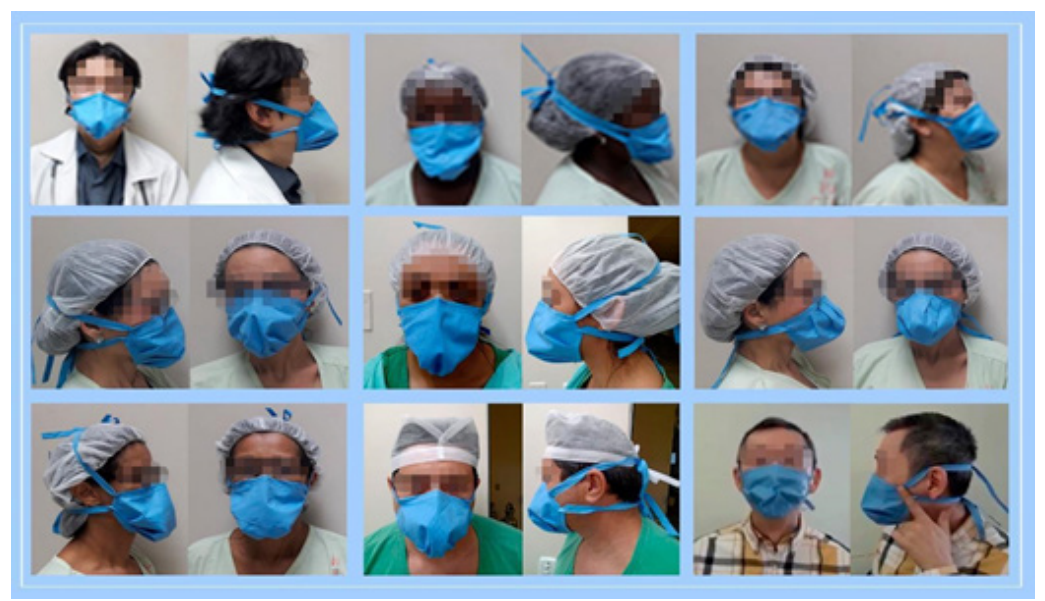

Fonte: acervo das autoras (2020).

Ao analisar a Figura 5, percebe-se que a configuração formal e espacial do produto se altera conforme as interações estabelecidas com a face do usuário. De modo geral, em rostos mais finos a máscara projeta o volume do "bico de pato" para frente, enquanto em rostos mais largos, este volume é distribuído de forma mais suave pela extensão lateral do rosto. Esta situação ocorre devido à dimensão e localização das pregas, que foram planejadas para garantir a mobilidade do material e permitir que o ajuste e a vedação se fizessem eficientes no maior número de usuários possível.

Além das questões de dimensionamento e ajuste, também foi avaliada a relação de uso no que diz respeito às formas de posicionar o produto no rosto ao vestir - detectando-se, inclusive, casos em que foi vestida ao contrário, isto é, a parte que deveria estar no nariz estava no queixo - bem como o manuseio das 


\section{Design, saúde e integração social...máscara de alta proteção AZUL-A98}

BARBOSA, T. A. M. et al

tiras durante a amarração, a posição das amarras na cabeça, a tração e pressão da máscara sobre o rosto, além de possíveis interações estabelecidas entre essa e os acessórios (como óculos) e/ou outros EPIs utilizados em concomitância.

Por meio dos feedbacks relatados durante o teste de usabilidade, constatouse $\mathrm{o}$ alto grau de interesse destes profissionais/usuários, particularmente, no que se refere à expectativa da obtenção de um modelo ergonômico e esteticamente agradável, que apresentasse melhor vestibilidade e conforto respiratório em comparação aos existentes.

Quanto à aceitação dos protótipos testados, no que se refere à configuração de forma, ficou evidente a preferência pelos modelos com estéticas mais tradicionais - semelhantes a produtos já difundidos no mercado e naturalmente absorvidos no contexto de uso destes usuários - em detrimento dos modelos considerados mais inovadores pela equipe de projeto.

Nesse sentido, Sanches (2017) pondera que os conceitos simbólicos atribuídos a um objeto não são qualidades fixas, e que seu significado é construído pela integração da percepção humana, com o tempo, o espaço, a cultura e a memória. Segundo a autora:

[...] mesmo que a interpretação do conteúdo não seja permanente e esteja circunstanciada por repertórios individuais e contexto, as percepções de sentido provocadas pelo artefato se efetivarão apenas se o suporte formal/visual estiver organizado de modo a estimular associações peculiares aos universos em que transitam os usuários interpretadores (SANCHES, 2017, p. 42).

Considerando as análises dos resultados obtidos na fase de testes de usabilidade procedeu-se, então, refinamentos tanto na modelagem, quanto na 
Projética, Londrina, v. 11, n. 1, supl. Design de Moda, p. 276-308, maio 2020

dimensão do produto (Figura 6), para que seu uso pudesse ser estendido a um maior número de profissionais/usuários, alcançando um elevado índice de aceitação e aprovação.

Figura 6 - Refinamento na modelagem e dimensão do produto

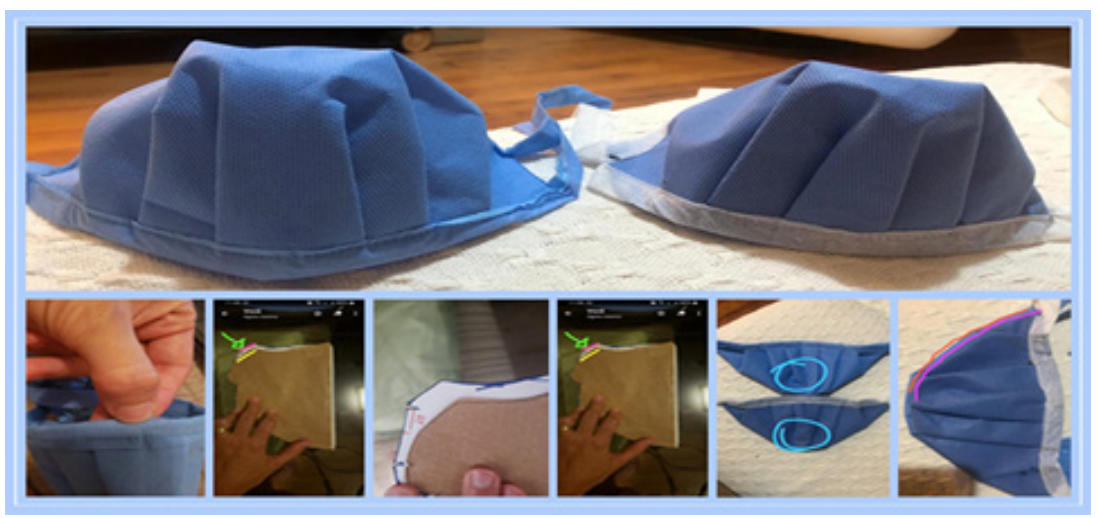

Fonte: acervo das autoras (2020).

As definições técnicas e de material, a forma obtida a partir do uso das pregas, bem como do seu posicionamento, potencializaram a solução encontrada para maximizar a vedação. A diferenciação desse novo modelo de EPI, consiste na eliminação da costura central (Figura 7) obtido a partir de um design adequado à função, que quebra o estereótipo da técnica única de costura central, para obter a forma deste tipo de produto.

Figura 7 - Resultado do produto Máscara de Alta Proteção AZUL-A98

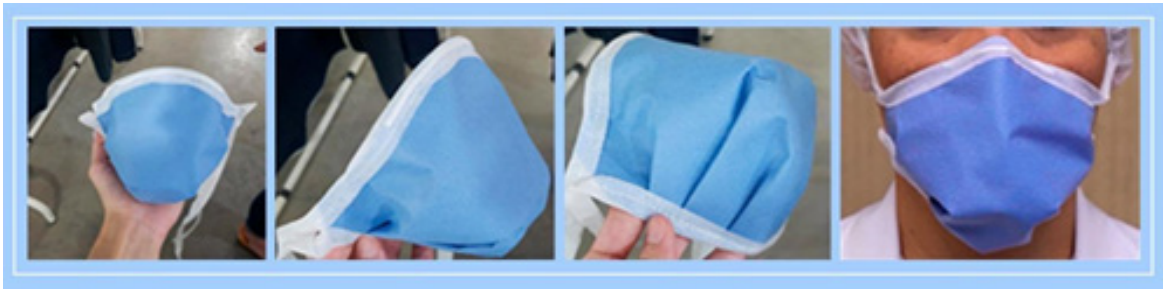

Fonte: acervo das autoras (2020). 
Design, saúde e integração social...máscara de alta proteção AZUL-A98

BARBOSA, T. A. M. et al

\section{A MODELAGEM NO ATENDIMENTO ÀS DEMANDAS PRODUTIVAS}

Especificamente na dimensão produtiva, a modelagem plana bidimensional (Figura 8) foi desenvolvida considerando, além dos critérios descritos anteriormente, as questões de aproveitamento do material, pois ao utilizar folhas de SMS com dimensão $120 \times 120 \mathrm{~cm}$, foi possível obter um encaixe com 30 partes da máscara (15 unidades de produto) e 94\% de aproveitamento. Além disso, sugeriu-se que as tiras de amarração fossem confeccionadas em TNT comum, para reduzir o custo de produção e permitir melhor utilização do SMS.

Para melhor compreensão da modelagem no contexto de montagem do produto, na Figura 9, apresenta-se a Sequência Pictórica de Procedimentos (SPP), representando graficamente o processo.

Figura 8 - Modelagem da máscara AZZUL-A98

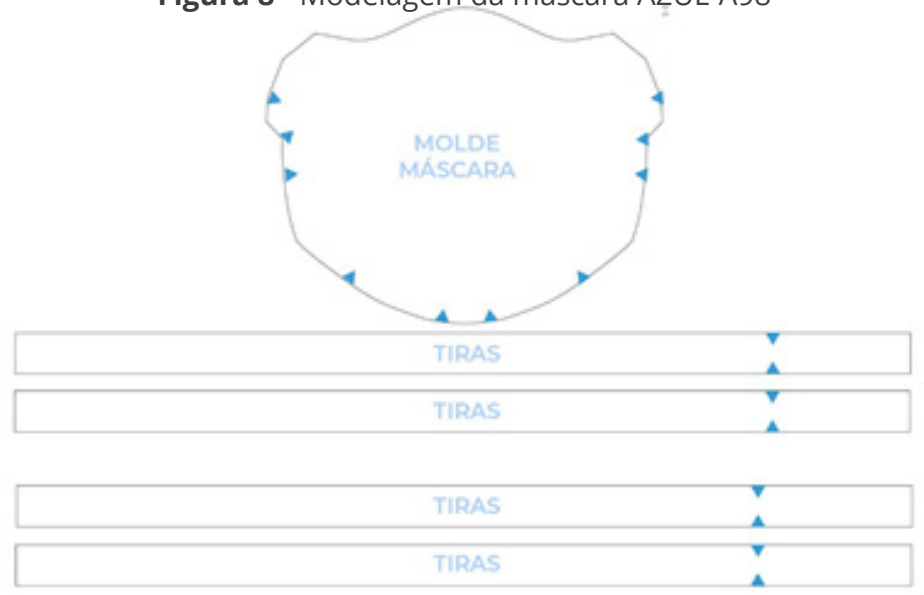

Fonte: acervo das autoras (2020). 
Projética, Londrina, v. 11, n. 1, supl. Design de Moda, p. 276-308, maio 2020

Figura 9 - Processo de montagem da Máscara de Alta Proteção AZUL-A98, por meio da SPP

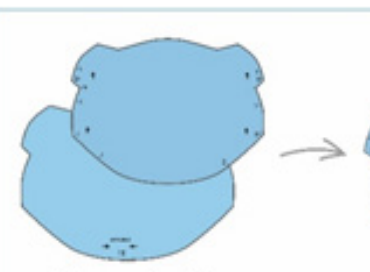

1. Ajustar as duas folhas de modo gue os piques se colcidam.

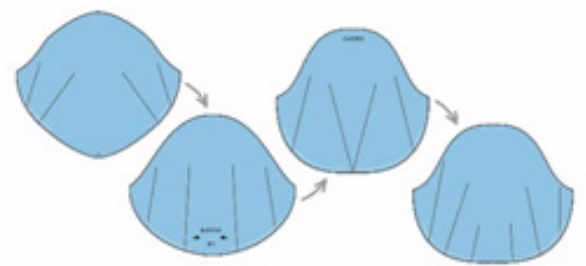

5. Apbso fechamento de todas as pregas, vire a mascara do lado avesso, una o final das pregas 2 e 3 nos plques indicados no molde, para formar a prega S. Esta prega, é urna mascara.

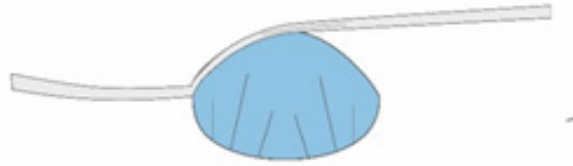

7. Dobre a tira superior ao meio e costure até a marcaçac do pique 1
Encabre a 1 tae

Encawe a lateral da máscara no pique 1, costure ate a metade, insira o lacre dentro da tira e costure até 0

pique 2

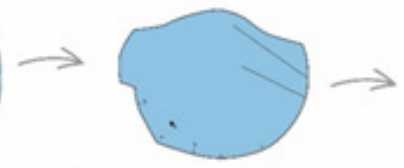

3. Fechar as pregas 2 e 3 girando as laterais para que as partes se modo a geratevitumente de para acomedar o queixo e o nariz.

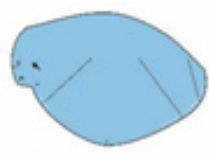

4. Fechar a prega 4.

Fonte: acervo das autoras (2020).

Considerando a demanda deste tipo de EPI em âmbito mundial, entendese que este novo modelo integra a funcionalidade dos materiais e da forma no atendimento aos requisitos de vedação, proteção. Além disso, o uso do SMS, somado a facilidade de produção decorrente da simplificação dos processos de costura, culminaram no baixo custo do produto e, consequentemente, em um dos principais diferenciais do projeto. Os custos diretos dos insumos utilizados para a produção de uma unidade da máscara deste projeto, estão listados na Quadro 1. 
Design, saúde e integração social...máscara de alta proteção AZUL-A98

BARBOSA, T. A. M. et al

Quadro 1 - Custos da Máscara de Alta Proteção Azul-A98

\begin{tabular}{|l|l|}
\hline MATERIAL & CUSTO \\
\hline SMS & 0,12 \\
\hline TNT para tiras & 0,066 \\
\hline Linha & 0,01 \\
\hline Clipe Nasal & 0,008 \\
\hline TOTAL & $\mathbf{R} 0,204$ \\
\hline
\end{tabular}

Fonte: acervo das autoras (2020).

Não foram incluídos os cálculos de Mão de Obra (MOD), tributação e outros custos indiretos, devido ao trabalho voluntário das indústrias de confecção parceiras e outros atores sociais, que doaram mão de obra para a produção das máscaras, nesse momento de pandemia. Mas, para direcionar ações futuras, registrou-se um tempo de 5 minutos para a produção de uma unidade da máscara AZUL-A98. Vale ressaltar que esta cronometria não considerou o sequenciamento de operações em linha de produção.

\section{A COMUNICAÇÃO DO PROJETO - DESIGN DIGITAL}

A mídia digital está a cada dia sendo mais utilizada, tanto para lazer como para trabalho. Em função da pandemia da Covid-19 e a necessidade do isolamento social, muitas pessoas estão aprendendo a usar a mídia digital e novos canais para se comunicarem. Nesse sentido, o meio mais eficiente, atualmente, é o digital, considerando os canais como site e rede social essenciais para a entrega da informação do projeto de modo eficiente, os quais a maioria das pessoas já estão habituadas a utilizar em seu dia a dia. 
Projética, Londrina, v. 11, n. 1, supl. Design de Moda, p. 276-308, maio 2020

Para tanto, foi desenvolvido pela universidade um site ${ }^{7}$ específico para disseminação das informações sobre a pandemia, e pela docente ${ }^{8}$ do departamento de design, uma página específica para o projeto social, referente a criação e implantação de um modelo para a confecção própria de máscaras hospitalares em SMS. (UNIVERSIDADE ESTADUAL DE LONDRINA, 2020).

Para obter uma comunicação atrativa e, mas simplificada, valeu-se de vídeos explicativos e sequência pictórica de procedimentos, com o objetivo de promover maior compreensão da informação, além da experiência do usuário, independentemente de seu nível de usabilidade com a mídia digital, considerando aspectos de navegabilidade, interface amigável e simples e hierarquia da informação, resultando em soluções de comunicação relevantes que melhoram a relação do usuário com a interface.

A partir dos resultados alcançados para o novo modelo de máscara intitulado "Máscara de alta proteção AZUL-A98" compilou-se dados técnicos, de materiais e de processos envolvidos, visando torná-lo público via site e com todas as informações necessárias, para que qualquer pessoa ou instituição interessada pudesse replicar o projeto, considerando as diferentes realidades contextuais envolvidas.

A arquitetura da informação para o site foi planejada, considerando a experiência do usuário em diversos níveis, desde inicial até avançado. Assim, a informação foi hierarquizada conforme representado na figura 10, a seguir.

[7] https://www.uelcontracoronavirus.com/

[8] Profa. Dra. Seila Cibele Sitta Preto, responsável pelo desenvolvimento do material gráfico e digital do projeto 
Design, saúde e integração social...máscara de alta proteção AZUL-A98

BARBOSA, T. A. M. et al

Figura 10 - Arquitetura e hierarquia da informação

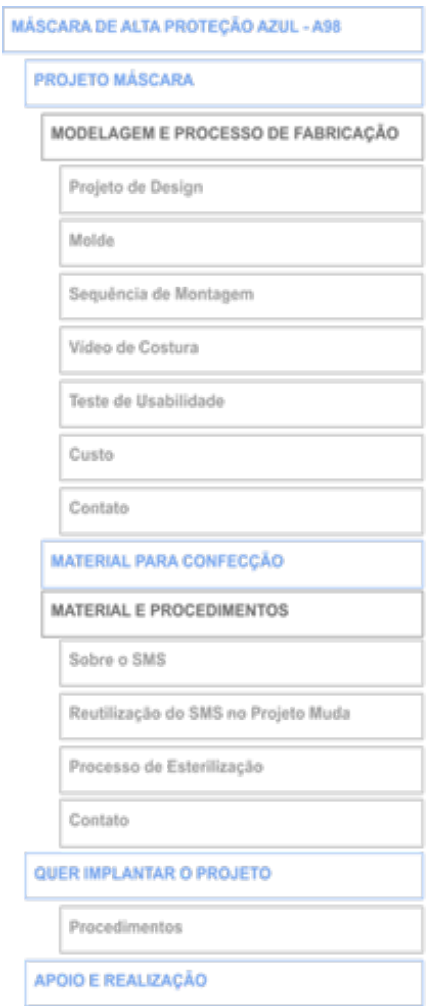

\begin{tabular}{|c|}
\hline MÁSCARA CIRUURGICA TRADICIONAL. \\
\hline PROJETO MÁSCARA \\
\hline MODELAGEM E PROCESSO DE FABRICAÇĀO \\
\hline Manual Técnice \\
\hline Molde \\
\hline Video de Costura \\
\hline Contate \\
\hline MATERIAL PARA CONFECÇĀO \\
\hline MATERIAL E PROCEDIMENTOS \\
\hline Sobre o SMS \\
\hline Reutilizaçào do SMS no Projeto Muda \\
\hline Processso de Esterilizaçâo \\
\hline Contate \\
\hline QUER IMPLANTAR O PROJETO \\
\hline Procidimentos \\
\hline APOIO E REALUZAÇǞO \\
\hline
\end{tabular}

Fonte: acervo das autoras (2020).

Utilizou de um sistema de botões com a finalidade de deixar sintetizado e objetivo as suas respectivas informações.

O uso das redes sociais foi planejado para potencializar a disseminação do projeto social por meio da criação de posts específicos, direcionados por links para o site, o qual possui de modo detalhado a informação.

Foi realizada a entrega formal dos resultados deste projeto à diretoria do HU (Figura 11), por meio de um reservado evento (atendendo as normas de distanciamento social, impostas pelo Ministério da Saúde) convocado pela reitoria 
Projética, Londrina, v. 11, n. 1, supl. Design de Moda, p. 276-308, maio 2020

da universidade para apresentação dos resultados junto a diversos os meios de comunicação de Londrina e região, os quais em muito contribuíram para dar visibilidade do resultado alcançado para toda a sociedade, e não somente à comunidade universitária.

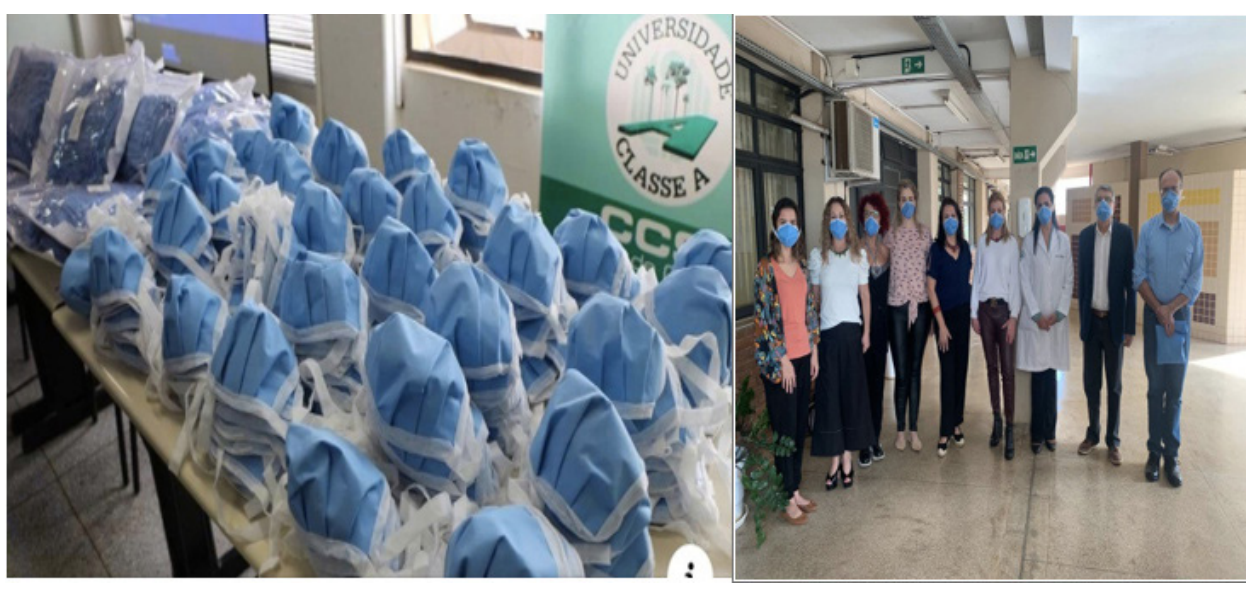

Fonte: acervo das autoras (2020).

Além do site e da ação de divulgação pelas redes sociais, foi organizado um conjunto de ações promocionais do projeto, como reportagem, para oficializar a publicação da pesquisa; lives realizadas para esclarecimento do projeto, publicação de posts nas redes sociais oficiais da universidade, compartilhamento nas redes sociais oficiais dos cursos de graduação envolvidos e desenvolvimento de hashtags para facilitar a busca de conteúdo, tais como: \#mascaraazulhospitalaruel; \#uelcontracoronavirus; \#designdemodauel; \#projetomudauel; \#engajamentosocialuel; \#projetosocialuel; \#pesquisauel. 
Design, saúde e integração social...máscara de alta proteção AZUL-A98

BARBOSA, T. A. M. et al

\section{A IMPLEMENTAÇÃO DO PROJETO - DESIGN SOCIAL}

O cenário social imposto pela pandemia e as novas configurações de sociedade que surgirão pós Covid-19, exigirão do design uma nova forma de atuação, centrada na inovação social e na sustentabilidade. Moraes (2010) propõe que, para ser um agente de mudança social, é preciso que o design do futuro considere os serviços, seus principais campos de atuação, as mudanças sociais e tecnológicas, bem como as redes sociais colaborativas.

Considerando o caráter interdisciplinar do projeto, o atual contexto social e a necessidade de manter o estoque do $\mathrm{HU}$ em constante abastecimento durante a crise, diversos atores sociais colaboraram na implementação do projeto. Como registro deste processo, cabe destacar a parceria entre o curso de Design de Moda e a Molde.me, empresa de tecnologia que propõe soluções em modelagem computadorizada para o vestuário. Devido à disponibilidade de acesso integral à plataforma, a modelagem das máscaras pôde ser desenvolvida e disseminada de forma segura nas mídias digitais.

O projeto recebeu, de uma mobilização voluntária da sociedade civil, doações de matéria-prima para a confecção de um lote de 15 mil máscaras. A 3Albe, empresa de insumos hospitalares e um dos fornecedores do HU, foi um dos parceiros que contribuiu com doação expressiva de SMS. Um grupo de mulheres, liderado por uma funcionária do HU, também participou da ação doando SMS, e outras empresas da região contribuíram com doações de TNT convencional e clipe nasal.

Para viabilizar a produção deste lote inicial, diversas indústrias de confecção de Londrina e região atuaram como parceiros voluntários. Vale destacar a grande contribuição da empresa Cris Jeans, localizada na cidade de Cambé, que se responsabilizou pela etapa de corte das máscaras durante todo o período de 
Projética, Londrina, v. 11, n. 1, supl. Design de Moda, p. 276-308, maio 2020

pandemia, bem como das empresas Di Hoffmann Camisaria e Santa Setta que produziram quantitativo suficiente para formação de um estoque inicial.

Resgatando os conceitos de Mccoy (2018), que entende que designers devem atuar como bons cidadãos e participar na formação do governo e da sociedade, incentivando, assim, a participação de outros atores sociais, os docentes responsáveis pelo projeto ampliaram as possibilidades de produção, por meio de uma ação social estabelecida com a Penitenciária Estadual de Londrina (PEL I).

Por intermédio da CODEL - Instituto de Desenvolvimento de Londrina, a parceria firmada com a PEL I, possibilitou a implantação de uma célula de produção constante de máscaras, que poderá manter o estoque do HU abastecido, durante o período necessário. Para isto, os detentos que trabalham no ateliê de costura da unidade receberam treinamento, oferecido por docentes participantes do projeto, para conhecerem as etapas de confecção do produto.

A fim de sanar possíveis dúvidas durante a produção, um painel com a sequência de procedimentos de montagem foi produzido e disponibilizado aos detentos. E o primeiro lote produzido na PEL I, passou por acompanhamento e conferência, realizados pela equipe de projeto, possibilitando a redução de perdas e defeitos no final do processo. 
Design, saúde e integração social...máscara de alta proteção AZUL-A98

BARBOSA, T. A. M. et al

Figura 12 - Mapeamento e Sistema Produto-Serviço-PSS (Máscara AZUL-A98)

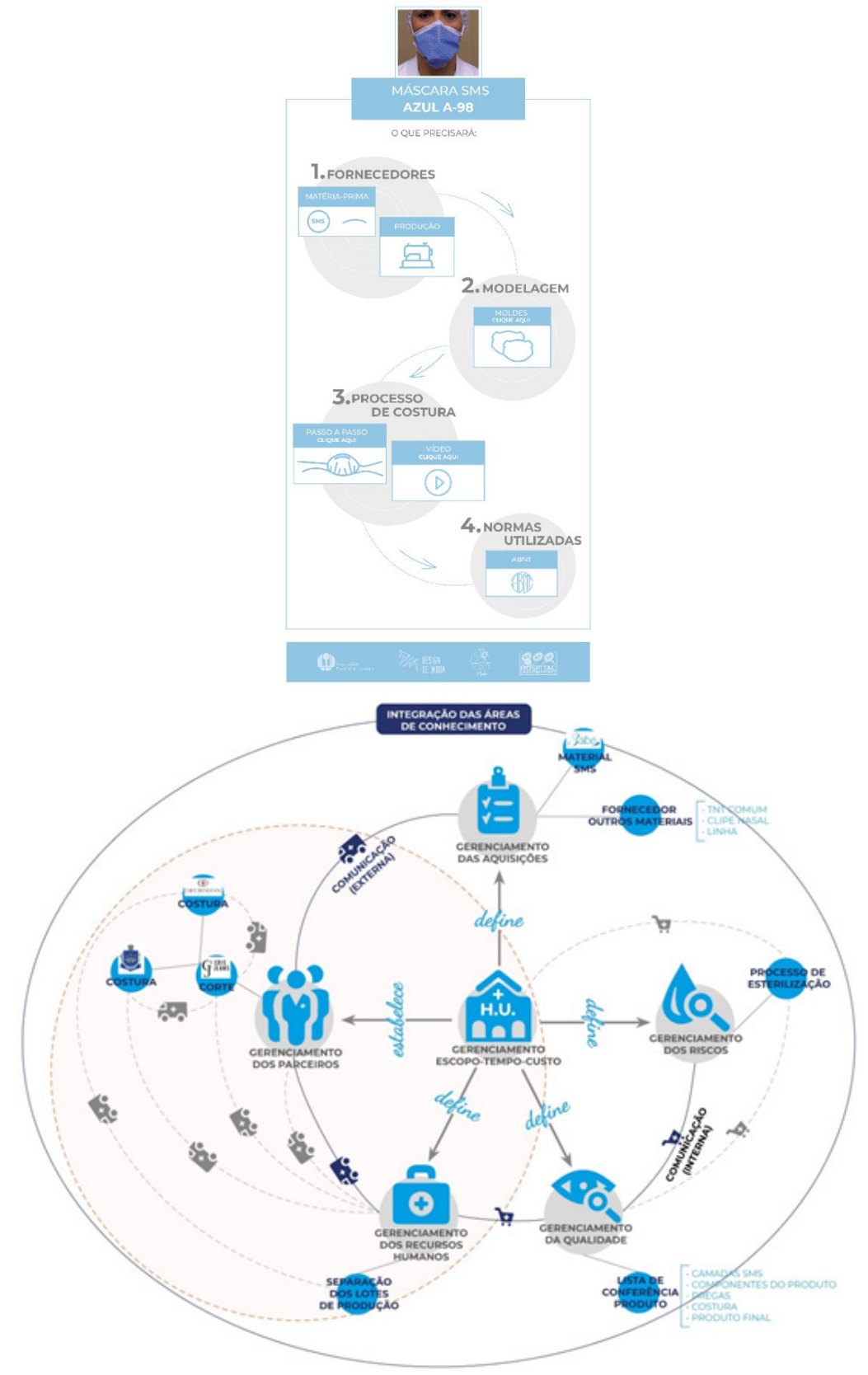

Fonte: acervo das autoras (2020). 
Projética, Londrina, v. 11, n. 1, supl. Design de Moda, p. 276-308, maio 2020

A Figura 12 demonstra uma proposta de um Sistema Produto-Serviço - PSS, criada a partir da mobilização social descrita. Esse sistema será disponibilizado nas mídias digitais para que outros hospitais também possam implementar o modelo de produção adotado neste projeto.

\section{CONSIDERAÇÕES FINAIS}

Todas as ações relatadas neste artigo foram, criteriosamente, definidas para atender aos objetivos delimitados na fase inicial. Ao analisar os resultados, a equipe entende que o projeto extrapolou o escopo da demanda inicial do HU, uma vez que, além de uma nova máscara, foi desenvolvido um modelo de gestão de design.

Tal modelo apresentado na forma de um PSS, só pôde ser desenvolvido por haver a efetivação do processo de design, a integração de conhecimento entre as áreas e a capacidade de atuação das pesquisadoras no contexto estudado. Isto posto, entende-se que o design de moda pode responder e atuar em demandas sociais urgentes, trabalhando junto a outras áreas para, também, ajudar a salvar vidas.

[9] Sistema Produto-Serviço é um modelo de oferta, que proporciona um mix integrado de produtos e serviços, que em conjunto são capazes de satisfazer uma demanda particular do consumidor (para entrega de uma "unidade de satisfação") baseada em interações inovadoras entre os atores (stakeholders) do sistema de produção de valores (sistema de satisfação), onde o interesse econômico e competitivo dos fornecedores procura continuamente novas soluções ambientalmente benéfica. (VEZZOLI; KOHTALA; SRINIVASA, 2018, p. 64). 


\section{Design, saúde e integração social...máscara de alta proteção AZUL-A98}

BARBOSA, T. A. M. et al

Em relação ao atendimento dos requisitos de projeto da máscara cirúrgica de alta proteção AZUL-A98, considera-se que todos estão contemplados no produto, mas entende-se como principais critérios de inovação: a) possibilidade de reutilização do SMS, que embora fosse gerenciado como refugo no $\mathrm{HU}$, tem o potencial de filtração exigido pela normatização e foi o responsável pelo baixo custo do produto e caráter sustentável do projeto; b) exploração do recurso construtivo de modelagem "prega", para gerar uma configuração formal de produto que não se distanciasse do estereótipo popular dos usuários, mas fosse capaz de eliminar a costura central, permitir a vedação das vias respiratórias do usuário, possibilitar a mobilidade do material para ajustar ao maior número de faces e auxiliar a movimentação do fluxo de ar durante a respiração.

A necessidade de produção constante e em larga escala, fez com que uma estrutura articulada de diversos atores sociais fosse implementada no HU. Esta rede de parceiros, foi organizada como um sistema e compartilhado nas mídias digitais (Figura 12), para que outros hospitais e instituições pudessem replicar o projeto e construir suas próprias células de abastecimento do EPI máscara. Entende-se que foi alcançada a perspectiva social do design, com ações pautadas não somente nas necessidades dos usuários, mas em todo contexto político, econômico e social do momento.

Por fim, cabe aqui destacar, que decorrente do contexto posto pela pandemia causada pela Covid-19, a maior parte das ações aqui descritas, foram realizadas respeitando as medidas de isolamento social. A equipe de projeto trabalhou de forma remota e encontros presenciais foram realizados apenas em momentos de extrema necessidade. Esta configuração de trabalho imposta, permite a reflexão sobre novas possibilidades do fazer design e de gerenciar projetos, na era pós-pandemia. 
Projética, Londrina, v. 11, n. 1, supl. Design de Moda, p. 276-308, maio 2020

\section{REFERÊNCIAS}

1. AGÊNCIA NACIONAL DE VIGILÂNCIA SANITÁRIA. Resolução - RDC Nº 356, de 23 de março de 2020. Dispõe, de forma extraordinária e temporária, sobre os requisitos para a fabricação, importação e aquisição de dispositivos médicos identificados como prioritários para uso em serviços de saúde, em virtude da emergência de saúde pública internacional relacionada ao SARS-CoV-2. Brasília, DF: Ministério da Saúde: Agência Nacional de Vigilância Sanitária. Disponível em: http://www.in.gov.br/en/web/dou/-/resolucao-rdc-n-356-de-23-de-marco-de-2020-249317437. Acesso em: 20 abr. 2020.

2. ASSOCIAÇÃO BRASILEIRA DE ENFERMEIROS DE CENTRO CIRÚRGICO, RECUPERAÇÃO ANESTÉSICA E CENTRO DE MATERIAL E ESTERILIZAÇÃO - SOBECC. Diretrizes de práticas em enfermagem cirúrgica e processamento de produtos para a saúde. 7. ed. ed. rev. atual. Barueri: Manole, 2017.

3. ASSOCIAÇÃO BRASILEIRA DE NORMAS TÉCNICAS. ABNT NBR 13697: equipamentos de proteção respiratória: filtros para partículas. Rio de Janeiro: ABNT, 2010.

4. ASSOCIAÇÃO BRASILEIRA DE NORMAS TÉCNICAS. ABNT NBR 13698: equipamento de proteção respiratória: peça semifacial filtrante para partículas. Rio de Janeiro: ABNT, 2017.

5. ASSOCIAÇÃO BRASILEIRA DE NORMAS TÉCNICAS. ABNT NBR 14783: não tecido para artigos de uso odonto-médico-hospitalar determinação de eficiência de filtração bacteriológica. Rio de Janeiro: ABNT, 2002.

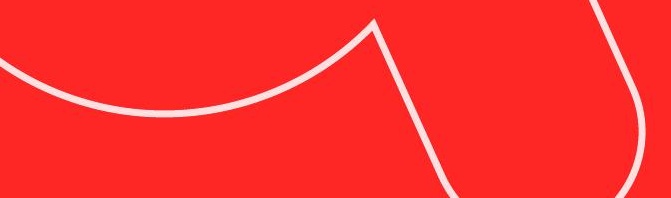


Design, saúde e integração social...máscara de alta proteção AZUL-A98

BARBOSA, T. A. M. et al

6. ASSOCIAÇÃO BRASILEIRA DE NORMAS TÉCNICAS. ABNT NBR 15052: artigos de uso odonto -médico-hospitalar máscara cirúrgica. Rio de Janeiro: ABNT, 2004.

7. BAXTER, Mike. Projeto de produto: guia prático para o design de novos produtos. São Paulo: E. Blucher, 2011.

8. EMÍDIO, Lucimar de Fátima Bilmaia. Modelo MODThink: o pensamento de design aplicado ao ensino-aprendizagem e desenvolvimento de competências cognitivas em modelagem do vestuário. 2018. Tese (Doutorado) - Universidade Estadual Paulista, São Paulo, SP, 2018.

9. IIDA, Itiro. Ergonomia, projeto e produção. São Paulo: Edgard Blucher, 2005.

10. KARLINER, Joshua; GUENTHER, Robin. Agenda global hospitais verdes e saudáveis. 2012. Disponível em: http://greenhospitals.net/wpcontent/uploads/2012/03/GGHHA-Portugese.pdf. Acesso em: 27 set. 2013.

11. LAKATOS, Eva Maria; MARCONI, Marina de Andrade. Metodologia científica. 7. ed. São Paulo: Atlas, 2017.

12. MCCOY, Katherine. Good citizenship: design as a social and political force. In: HELLER, Steven; VIENNE, Véronique (ed.). Citizen designer: perspectives on design responsibility. 2. ed. New York: Allworth Press, 2018. p. 188-195.

13. MORAES, Anamaria de; MONT'ALVÃO, Claudia. Ergonomia: conceitos e aplicações. 4. ed. Teresópolis: 2AB, 2010. 
Projética, Londrina, v. 11, n. 1, supl. Design de Moda, p. 276-308, maio 2020

14. MORAES, Dijon. Metaprojeto: o design do design. São Paulo: Blücher, 2010.

15. ORGANIZAÇÃO MUNDIAL DE SAÚDE. Advice on the use of masks in the context of COVID-19; 2020. Disponível em: https://www.who.int/publications-detail/advice-on-the-use-of-masks-in-the-community-during-home-care-and-in-healthcare-settings-in-the-context-of-the-novel-coronavirus-(2019-ncov)-outbreak. Acesso em: 27 abr. 2020.

16. SANCHES, Maria Celeste de F. Moda e projeto: estratégias metodológicas em design. São Paulo: Estação das Letras e Cores, 2017.

17. SOUZA, Patrícia de Mello. Estratégias de construção para estruturas têxteis vestíveis. 2013. Tese (Doutorado) - Faculdade de Arquitetura, Artes e Comunicação, Universidade Estadual Paulista, Bauru, 2013.

18. THIOLLENT, Michel. Metodologia da pesquisa-ação. 18. ed. São Paulo: Editora Cortez, 2011.

19. THIOLLENT, Michel. Pesquisa-ação nas organizações. 2. ed. São Paulo: Atlas, 2009.

20. UNIVERSIDADE ESTADUAL DE LONDRINA. UEL Contra o Coronavírus. Apresentação. Disponível em: https://www.uelcontracoronavirus.com/. Acesso em: 27 abr. 2020.

21. VEZZOLI, Carlo; KOHTALA, Cindy; SRINIVASA, Amrit. Sistema produto + serviço sustentável: fundamentos. Traduzido por Aguinaldo dos Santos. Curitiba, PR: Insight, 2018.

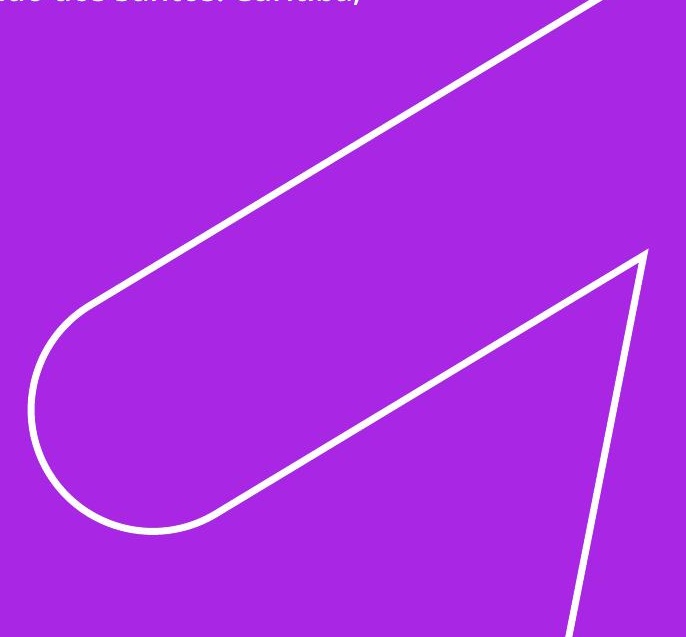

